\title{
Commentary
}

\section{Eaten Alive}

\section{Autophagy and Neuronal Cell Death after Hypoxia-Ischemia}

\author{
Charleen T. Chu, M.D., Ph.D. \\ From the Department of Pathology/Division of Neuropathology, \\ Center for Neuroscience and Pittsburgh Institute for \\ Neurodegenerative Diseases, University of Pittsburgh School of \\ Medicine, Pittsburgh, Pennsylvania
}

Hypoxic-ischemic injury to the brain is a major cause of morbidity and mortality in infants and adults. Despite advances in obstetric care, the incidence of cerebral palsy from perinatal hypoxia-ischemia remains at $>2$ per 1000 births, ${ }^{1}$ and arterial ischemic stroke occurs in $\sim 1$ of 4000 term infants. ${ }^{2}$ In the United States, stroke is the third leading cause of death in adults (Centers for Disease Control and Prevention National Center for Health Statistics), and hypoxic-ischemic brain injury can be prominent in survivors of cardiac arrest, the leading cause of death. As with any pathological insult, multiple pathways of injury and adaptation are activated after hypoxic-ischemic brain injury. Delineating positive and negative contributions of these pathways to neuronal cell loss is critical for development of neuroprotective therapies but can be exceedingly difficult to detangle. Dying neurons in the ischemic brain exhibit a range of morphologies ascribed to apoptotic, autophagic, and oncotic (necrotic) cell death pathways, ${ }^{3}$ although the role of autophagy as a mediator of cell death has been controversial. ${ }^{4,5}$ In this issue of The American Journal of Pathology, Koike and colleagues ${ }^{6}$ present the first in vivo evidence of neuronal cell death requiring autophagy in the mammalian brain.

\section{The Janus-Faced Role of Autophagy in the Brain}

Autophagy is one of the most rapidly growing fields in biomedical research, undergoing an explosion of interest reminiscent of that exhibited for apoptosis in the 1990's. ${ }^{7}$ Macroautophagy was traditionally thought of as a conserved, relatively nonselective response to nutrient stresses, involving sequestration of portions of the cytoplasm into membrane-bound vacuoles targeted for lysosomal degradation. More recently, it has become appar- ent that levels of autophagy are exquisitely regulated and that autophagy-related processes play central roles in development, aging, and the pathogenesis of cancer, neurodegeneration, and infectious diseases. ${ }^{8-13}$

The role of autophagy as a mediator of cell death has become generally accepted in some fields, ${ }^{3,14}$ but alternative interpretations have been proposed. ${ }^{4}$ Earlier studies used phosphoinositide 3-kinase inhibitors to inhibit and thus implicate stress-induced autophagy in a prodeath role. ${ }^{15,16}$ Other studies used rapamycin to demonstrate an important beneficial role for autophagy in aggregate clearance in neurodegenerative conditions. ${ }^{17}$ However, both classes of drugs may have diverse effects on cells that extend beyond autophagy regulation to include modulation of survival/death kinases by 3-methyladenine ${ }^{15}$ and regulation of protein synthesis and differentiation through mTOR. ${ }^{18}$ Thus, the issue of whether autophagy observed in dying cells reflects a death mechanism, failed adaptation, or epiphenomenon requires additional complementary approaches to establish causality.

The identification of autophagy (Atg) genes involved in specific ubiquitin-like conjugation reactions that are essential for extension of autophagic membranes has revolutionized the field, ${ }^{7,19}$ allowing for development of specific markers for autophagic vacuole formation and maturation, ${ }^{20}$ and providing molecular genetic tools for knocking out or knocking down essential Atg gene products. In brief, Atg7 acts as an E1-activating enzyme to produce high-energy thioester bonds involving two ubiquitin-fold proteins LC3/Atg8 and Atg12, which are transferred to their E2 enzymes Atg3 and Atg10, respectively. These E2-conjugating enzymes act to transfer LC3/Atg8 and Atg12 to phosphatidylethanolamine and Atg5, their respective targets at the growing autophagic membrane. Although complete knockout of Atg5 is required to abolish autophagy, ${ }^{21}$ a reduction in the expression level of

Supported by the National Institutes of Health (grants AG026389, NS053777, and DC009120)

Accepted for publication November 13, 2007.

Address reprint requests to Charleen T. Chu, M.D., Ph.D., Division of Neuropathology, Room A-516 UPMC Presbyterian, 200 Lothrop St., Pittsburgh, PA 15213. E-mail: ctc4@pitt.edu or chuct@post.harvard.edu. 
Atg proteins is sufficient to blunt robust autophagic vacuole induction observed during stress and injury. These knockdown studies have confirmed that certain forms of cell death require sufficient expression of Atg proteins to support stress-induced increases in autophagy, implicating autophagy in an active death-promoting role. ${ }^{22-25}$

On the other hand, knockout mouse studies targeting Atg5 or Atg7 elegantly demonstrate that neurons require at least basal levels of autophagy for maintenance of health and function in vivo. ${ }^{26,27}$ The chronic absence of autophagy results in build up of ubiquitinated protein aggregates in neuronal populations, accompanied by neurodegeneration and death of the mice within the first 2 months of life. Interestingly, neuronal populations most heavily affected by inclusions are not necessarily the most susceptible to degeneration, suggesting that inclusions may represent some degree of success in adapting to the underlying stress. Pediatric neurodegeneration is also seen with lysosomal storage diseases, although the primary deficit here is not induction of autophagy, but inadequate lysosomal clearance of sequestered material. Regardless of mechanism, it is clear that both initiation and successful completion of autophagic degradation are essential for basal neuronal health.

In contrast to the beneficial roles of physiological autophagy, the first study using Atg gene knockdowns to show involvement of pathological autophagy in neuronal cell death was published a year ago..$^{25}$ Just as pharmacological inhibitors may influence pathways beyond autophagy, the possibility that a given Atg protein may regulate processes other than autophagy needs to be considered. In neuronal cells, RNAi knockdown of LC3, Atg7, or Atg5 conferred protection from cell death ${ }^{25}$ and neurite degeneration in toxin and genetic models of Parkinson's disease, ${ }^{28}$ and RNAi targeting Atg5 and beclin1 protected $661 \mathrm{~W}$ cells from hydrogen peroxide injury. ${ }^{29}$ As it is unlikely that multiple Atg proteins would have the same hypothetical nonautophagy function, these cell culture studies indicate an active role for autophagy in neurodegeneration and some forms of neuronal cell death.

The current study in this issue of the AJP demonstrates that autophagy is robustly increased during neonatal and adult brain hypoxia-ischemia in vivo. ${ }^{6}$ Although caspase 3 is cleaved in $\sim 35 \%$ of hippocampal pyramidal neurons during injury, neither caspase 3-deficient nor caspaseactivated DNase (CAD)-deficient animals show any degree of protection, indicating the existence of additional cell death mechanisms. In these apoptosis-deficient animals, alternative apoptotic mediators such as caspase 7 and an unknown DNase appear to be induced, although the magnitude of the DNA laddering observed is slight compared to that exhibited by wild-type animals, suggesting that these compensations do not account for the degree of hippocampal loss exhibited in the injured hemisphere of apoptosis-deficient animals. Using conditional knockout mice deficient in brain Atg7, which show no signs of neurological abnormalities or inclusions until 3 weeks of age, Koike and colleagues ${ }^{6}$ further show that P7 mice lacking Atg7 in neurons exhibit dramatic protection from neonatal hypoxia-ischemia up to 7 days after hypoxic-ischemic injury. These intriguing results represent the first in vivo evidence that autophagy actively contributes to brain injury and neuronal cell death.

\section{Relationship between Autophagy and Apoptosis}

The mythical god Janus not only is depicted with two faces, analogous to the prosurvival and prodeath roles of autophagy, but also functions as the god of gates, beginnings and endings. The study by Koike and colleagues $^{6}$ elegantly demonstrates a crucial role for the autophagy E1 enzyme Atg7 as the gatekeeker of hypoxic-ischemic neuron death mediated by both apoptotic and nonapoptotic mechanisms. There are multiple potential points of interaction between apoptosis and autophagy, and these have been the subject of an excellent recent review. ${ }^{14}$

Although type II or autophagic programmed cell death was originally described as a distinct morphological form of developmental cell death lacking apoptotic features, in many systems there are features of both autophagy and apoptosis, ${ }^{30}$ with autophagy preceding apoptotic cell death. Although this is sometimes indicative of compensatory adaptation, ${ }^{31}$ molecular genetic evidence from a variety of systems indicate that autophagy-dependent processes are sometimes necessary to trigger apoptotic cell death. ${ }^{6,32}$

Teleologically speaking, autophagy may function similarly to other well known stress response pathways to mediate either successful repair or cell suicide, both of which would be adaptive in a multicellular organism. Imbalances between the extent of autophagy induction and the ability of the cell to complete autophagic degradation and recycling/regeneration of cellular components would create a state of autophagic stress and eventually autophagic cell death. ${ }^{11}$ Neuronal cells may be particularly susceptible to developing autophagic stress during aging, because of increased demand for autophagic clearance of damaged constituents, extensive dependence on anterograde and retrograde trafficking over long distances, and decreased degradative and biosynthetic reserves. ${ }^{11}$ Autophagic stress attributable to excessive injury-induced mitochondrial degradation is associated with caspase-independent cell death pathways, ${ }^{25,33,34} \mathrm{Au}$ tophagic stress attributable to impaired lysosomal function has also been shown to precede apoptosis in vivo. ${ }^{35}$

Dysregulation of calcium, as observed after acute or chronic autophagic stress, ${ }^{36,37}$ may play a key role in switching between autophagy and apoptosis because calpain-cleaved Atg5 mediates apoptosis. ${ }^{38}$ Although autophagy sometimes harnesses the apoptotic machinery for cell suicide, it is also clear that autophagic cell death can be executed independently of an intact apoptotic machinery. ${ }^{22,23}$ Indeed, it has been proposed that autophagic cell death is important mainly in apoptosisdeficient cells. ${ }^{4}$ Interestingly, mature neuronal cells tend to be relatively apoptosis-resistant, related to high expression of neuronal inhibitors of apoptosis. ${ }^{39}$ For example, although numerous apoptotic profiles are observed in postmortem brain tissues after hypoxic-ischemic injury in 
neonates, they are not readily observed in similarly injured adult brains (C.T.C., personal observation). Young rats injured by 6-hydroxydopamine show predominantly apoptotic morphology, whereas nonapoptotic cell death becomes prominent in 42-day-old rats subjected to the same insult. ${ }^{40}$ Notably, Koike and colleagues ${ }^{6}$ observed a greater degree of autophagy induction in adult mice subjected to hypoxic-ischemic injury, suggesting that autophagy-driven cell death may be even more significant in mature neurons.

\section{Mitochondrial Mechanisms and Future Questions}

Because the Atg7-deficient animals showed reductions in both caspase 3-dependent and -independent pathways of neuron death, continued investigation into molecular connections between autophagy and apoptosis is indicated. Mitochondria may very well play a key pivotal role, poised at the interface between life support and cell suicide. The proportion of the cellular mitochondrial complement that undergoes depolarization has been proposed to determine whether a stressed cell undergoes autophagy, apoptosis, or necrosis. ${ }^{41}$ Mitochondria also play key roles in calcium buffering, phospholipid metabolism, and cell signaling, each of which can be important for regulation of autophagy and cell death.

Although the concept of autophagic stress assumes that dysregulation of a fundamentally cytoprotective response leads to detrimental consequences when autophagic demand cannot be balanced by cellular reserves, ${ }^{11}$ it is also possible that the differences between physiological and pathological autophagy are mediated by fundamentally different pathways of induction. For example, a short mitochondrial form of p19ARF induces autophagy and caspase-independent cell death, ${ }^{42}$ and autophagy appears to be induced by this mechanism to fulfill a death-promoting role from the beginning. Autophagy and mitochondrial degradation can proceed independently of beclin 1 in toxin models of Parkinson's disease, ${ }^{25}$ suggesting fundamentally different upstream mechanisms and escape from potential beclin 1-Bcl-2-related regulation.

Mitochondrial oxidative stress is robustly induced in several brain pathologies associated with autophagy, including cerebral hypoxia-ischemia injury, ${ }^{6,43}$ traumatic brain injury, ${ }^{44}$ and Parkinsonian stresses. ${ }^{25}$ Direct stimulation of mitochondrial oxidative stress could serve to bypass the requirement for beclin 1, given that mitochondrial reactive oxygen species have been shown to function downstream of beclin 1-phosphoinositide-3 kinase signaling. ${ }^{45}$ Moreover, redox activation of mitochondrial pools of extracellular signal-regulated protein kinase contributes to toxicity, ${ }^{46}$ and MAPK/ERK kinase inhibitors confer protection from autophagic cell death ${ }^{25}$ and from hypoxic-ischemic, traumatic, and neurotoxic injuries. ${ }^{47}$

Another area for further study concerns the role of autophagy in white matter damage. Axonal tracts are susceptible to hypoxic-ischemic and traumatic injuries. Although not examined in the study by Koike and colleagues, ${ }^{6}$ dysregulated autophagy is implicated in axonal degeneration. ${ }^{48}$ Although neurite retraction may represent a short-term solution to promote survival of the neuron cell body, irreversible neurodegeneration is likely to result if excessive degradation cannot be balanced biosynthetically to re-establish function.

To summarize, a growing number of studies have used neuronal cells with reduced capacity for autophagy induction, and now mice deficient in brain Atg proteins, to show that autophagy can contribute to neurodegeneration and function as a gatekeeping mediator of apoptotic and nonapoptotic death pathways. Additional studies to address autophagy regulation under specific contexts, including oxidative neuronal injury, dysregulated calcium homeostasis, and neuron-specific compartments are required to facilitate potential future therapies to reduce neuropathological outcomes. If autophagic neurodegeneration and cell death result from imbalances between initiation and completion of autophagic recycling (autophagic stress), threshold-based therapies that strive to restore balance to the system without completely abolishing basal autophagy could be sought. If autophagic cell death results primarily from different mechanisms of activation, or simultaneous activation of adaptor systems that convert autophagy into a prodeath mechanism, threshold regulators may not be as effective as targeting the factors that determine commitment to neuron cell death.

\section{References}

1. Odding E, Roebroeck ME, Stam HJ: The epidemiology of cerebral palsy: incidence, impairments and risk factors. Disabil Rehabil 2006, 28:183-191

2. Nelson KB, Lynch JK: Stroke in newborn infants. Lancet Neurol 2004 3:150-158

3. Bredesen DE: Key note lecture: toward a mechanistic taxonomy for cell death programs. Stroke 2007, 38:652-660

4. Levine B, Yuan J: Autophagy in cell death: an innocent convict? J Clin Invest 2005, 115:2679-2688

5. Debnath J, Baehrecke EH, Kroemer G: Does autophagy contribute to cell death? Autophagy 2005, 1:66-74

6. Koike M, Shibata M, Tadakochi M, Gotoh K, Komatsu M, Waguri S, Kawahara N, Kuida K, Nagata S, Kominami E, Tanaka K, Uchiyama Y: Inhibition of autophagy prevents hippocampal pyramidal neuron death after hypoxic-ischemic injury. Am J Pathol 2008, 172:454-469

7. Klionsky DJ: Autophagy: from phenomenology to molecular understanding in less than a decade. Nat Rev Mol Cell Biol 2007, 8:931-937

8. Levine B, Klionsky DJ: Development by self-digestion: molecular mechanisms and biological functions of autophagy. Dev Cell 2004, 6:463-477

9. Cuervo AM, Bergamini E, Brunk UT, Droge W, French M, Terman A Autophagy and aging: the importance of maintaining "clean" cells. Autophagy 2005, 1:131-140

10. Kondo Y, Kanzawa T, Sawaya R, Kondo S: The role of autophagy in cancer development and response to therapy. Nat Rev Cancer 2005, 5:726-734

11. Chu CT: Autophagic stress in neuronal injury and disease. J Neuropathol Exp Neurol 2006, 65:423-432

12. Boland B, Nixon RA: Neuronal macroautophagy: from development to degeneration. Mol Aspects Med 2006, 27:503-519

13. Colombo MI: Autophagy: a pathogen driven process. IUBMB Life 2007, 59:238-242

14. Maiuri MC, Zalckvar E, Kimchi A, Kroemer G: Self-eating and selfkilling: crosstalk between autophagy and apoptosis. Nat Rev Mol Cell Biol 2007, 8:741-752 
15. Xue L, Fletcher GC, Tolkovsky AM: Autophagy is activated by apoptotic signalling in sympathetic neurons: an alternative mechanism of death execution. Mol Cell Neurosci 1999, 14:180-198

16. Florez-McClure ML, Linseman DA, Chu CT, Barker PA, Bouchard RJ, Le SS, Laessig TA, Heidenreich KA: The p75 neurotrophin receptor can induce autophagy and death of cerebellar Purkinje neurons. J Neurosci 2004, 24:4498-4509

17. Rubinsztein DC, DiFiglia M, Heintz N, Nixon RA, Qin Z-H, Ravikumar B, Stefanis L, Tolkovsky A: Autophagy and its possible roles in nervous system diseases, damage and repair. Autophagy 2005, 1:11-22

18. Swiech L, Perycz M, Malik A, Jaworski J: Role of mTOR in physiology and pathology of the nervous system. Biochim Biophys Acta (in press) DOI: 10.1016/j.bbapap.2007.08.015

19. Ohsumi Y: Molecular dissection of autophagy: two ubiquitin-like systems. Nat Rev Mol Cell Biol 2001, 2:211-216

20. Kimura S, Noda T, Yoshimori T: Dissection of the autophagosome maturation process by a novel reporter protein, tandem fluorescenttagged LC3. Autophagy 2007, 3:452-460

21. Hosokawa N, Hara Y, Mizushima N: Generation of cell lines with tetracycline-regulated autophagy and a role for autophagy in controlling cell size. FEBS Lett 2006, 580:2623-2629

22. Yu L, Alva A, Su H, Dutt P, Freundt E, Welsh S, Baehrecke EH, Lenardo MJ: Regulation of an ATG7-beclin 1 program of autophagic cell death by caspase-8. Science 2004, 304:1500-1502

23. Shimizu S, Kanaseki T, Mizushima N, Mizuta T, Arakawa-Kobayashi $\mathrm{S}$, Thompson CB, Tsujimoto $\mathrm{Y}$ : Role of Bcl-2 family proteins in a non-apoptotic programmed cell death dependent on autophagy genes. Nat Cell Biol 2004, 6:1221-1228

24. Chen Y, McMillan-Ward E, Kong J, Israels SJ, Gibson SB: Oxidative stress induces autophagic cell death independent of apoptosis in transformed and cancer cells. Cell Death Differ 2008, 15:171-182

25. Zhu JH, Horbinski C, Guo F, Watkins S, Uchiyama Y, Chu CT: Regulation of autophagy by extracellular signal-regulated protein kinases during 1-methyl-4-phenylpyridinium-induced cell death. Am J Pathol 2007, 170:75-86

26. Hara T, Nakamura K, Matsui M, Yamamoto A, Nakahara Y, SuzukiMigishima R, Yokoyama M, Mishima K, Saito I, Okano H, Mizushima $\mathrm{N}$ : Suppression of basal autophagy in neural cells causes neurodegenerative disease in mice. Nature 2006, 441:885-889

27. Komatsu M, Waguri S, Chiba T, Murata S, Iwata J, Tanida I, Ueno T, Koike M, Uchiyama Y, Kominami E, Tanaka K: Loss of autophagy in the central nervous system causes neurodegeneration in mice. Nature 2006, 441:880-884

28. Plowey ED, Cherra III SJ, Liu Y-J, Chu CT: Role of autophagy in G2019S-LRRK2-associated neurite shortening in differentiated SH-SY5Y cells. J Neurochem 2008, DOI: 10.1111/j.14714159.2008.05217.x

29. Kunchithapautham K, Rohrer B: Apoptosis and autophagy in photoreceptors exposed to oxidative stress. Autophagy 2007, 3:433-441

30. Lockshin RA, Zakeri Z: Apoptosis, autophagy, and more. Int J Biochem Cell Biol 2004, 36:2405-2419

31. Boya P, Gonzalez-Polo RA, Casares N, Perfettini JL, Dessen P Larochette N, Metivier D, Meley D, Souquere S, Yoshimori T, Pierron G, Codogno P, Kroemer G: Inhibition of macroautophagy triggers apoptosis. Mol Cell Biol 2005, 25:1025-1040

32. Scott RC, Juhasz G, Neufeld TP: Direct induction of autophagy by
Atg1 inhibits cell growth and induces apoptotic cell death. Curr Biol 2007, 17:1-11

33. Xue L, Fletcher GC, Tolkovsky AM: Mitochondria are selectively eliminated from eukaryotic cells after blockade of caspases during apoptosis. Curr Biol 2001, 11:361-365

34. Chu CT, Zhu JH, Cao G, Signore A, Wang S, Chen J: Apoptosis inducing factor mediates caspase-independent 1-methyl-4-phenylpyridinium toxicity in dopaminergic cells. J Neurochem 2005, 94:1685-1695

35. Walls KC, Klocke BJ, Saftig P, Shibata M, Uchiyama Y, Roth KA, Shacka JJ: Altered regulation of phosphatidylinositol 3-kinase signaling in cathepsin D-deficient brain. Autophagy 2007, 3:222-229

36. Brady NR, Hamacher-Brady A, Yuan H, Gottlieb RA: The autophagic response to nutrient deprivation in the $\mathrm{hl}-1$ cardiac myocyte is modulated by $\mathrm{Bcl}-2$ and sarco/endoplasmic reticulum calcium stores. FEBS J 2007, 274:3184-3197

37. Jennings JJ Jr, Zhu JH, Rbaibi Y, Luo X, Chu CT, Kiselyov K: Mitochondrial aberrations in mucolipidosis type IV. J Biol Chem 2006 281:39041-39050

38. Yousefi S, Perozzo R, Schmid I, Ziemiecki A, Schaffner T, Scapozza L, Brunner T, Simon HU: Calpain-mediated cleavage of Atg5 switches autophagy to apoptosis. Nat Cell Biol 2006, 8:1124-1132

39. Potts PR, Singh S, Knezek M, Thompson CB, Deshmukh M: Critical function of endogenous XIAP in regulating caspase activation during sympathetic neuronal apoptosis. J Cell Biol 2003, 163:789-799

40. Martí MJ, Saura J, Burke RE, Jackson-Lewis V, Jimenez A, Bonastre M, Tolosa E: Striatal 6-hydroxydopamine induces apoptosis of nigral neurons in the adult rat. Brain Res 2002, 958:185-191

41. Lemasters JJ, Nieminen AL, Qian T, Trost LC, Elmore SP, Nishimura Y, Crowe RA, Cascio WE, Bradham CA, Brenner DA, Herman B: The mitochondrial permeability transition in cell death: a common mechanism in necrosis, apoptosis and autophagy. Biochim Biophys Acta 1998, 1366:177-196

42. Reef S, Zalckvar E, Shifman O, Bialik S, Sabanay H, Oren M, Kimchi A: A short mitochondrial form of p19ARF induces autophagy and caspase-independent cell death. Mol Cell 2006, 22:463-475

43. Adhami F, Liao G, Morozov YM, Schloemer A, Schmithorst VJ, Lorenz JN, Dunn RS, Vorhees CV, Wills-Karp M, Degen JL, Davis RJ, Mizushima N, Rakic P, Dardzinski BJ, Holland SK, Sharp FR, Kuan CY: Cerebral ischemia-hypoxia induces intravascular coagulation and autophagy. Am J Pathol 2006, 169:566-583

44. Lai Y, Hickey RW, Chen Y, Bayir H, Sullivan ML, Chu CT, Kochanek PM, Dixon CE, Jenkins LW, Graham SH, Watkins SC, Clark RS: Autophagy is increased after traumatic brain injury in mice and is partially inhibited by the antioxidant gamma-glutamylcysteinyl ethyl ester. J Cereb Blood Flow Metab [Epub ahead of print] DOI: 10.1038/sj.jcbfm.9600551

45. Scherz-Shouval R, Shvets E, Fass E, Shorer H, Gil L, Elazar Z: Reactive oxygen species are essential for autophagy and specifically regulate the activity of Atg4. EMBO J 2007, 26:1749-1760

46. Kulich S, Horbinski C, Patel M, Chu C: 6-Hydroxydopamine induces mitochondrial ERK activation. Free Rad Biol Med 2007, 43:372-383

47. Chu CT, Levinthal DJ, Kulich SM, Chalovich EM, DeFranco DB Oxidative neuronal injury. The dark side of ERK1/2. Eur J Biochem 2004, 271:2060-2066

48. Yue Z, Wang QJ, Komatsu M: Neuronal autophagy: going the distance to the axon. Autophagy 2008, 4:94-96 